\title{
Neurorrafia término-lateral \\ Uma evolução da técnica de reparo de lesões de nervos periféricos?
}

\author{
Leandro Pretto Flores ${ }^{1}$ \\ Unidade de Neurocirurgia do Hospital de Base do Distrito Federal, Brasil
}

\section{RESUMO}

Apesar do avanço técnico obtido nas últimas décadas em relação ao reparo de lesões do sistema nervoso periférico a partir da introdução do microscópio cirúrgico e da monitorização eletrofisiológica transoperatória, o princípio fundamental da reconstrução nervosa pouco evoluiu, estando sempre baseado na sutura término-terminal. A neurorrafia término-lateral surgiu como opção terapêutica para as situações em que a utilização das técnicas convencionais não é possível. Baseia-se na capacidade que os axônios intactos do sistema nervoso periférico possuem de emitir prolongamentos colaterais, permitindo a reinervação de áreas vizinhas que foram previamente desnervadas. Reintroduzida há pouco mais de dez anos, a técnica vem sendo amplamente investigada tanto clínica quanto laboratorialmente, com resultados ainda inconclusivos. Este estudo apresenta uma revisão sistemática das principais publicações sobre esse tema, abrangendo as pesquisas experimentais, os estudos clínicos e as possíveis aplicações práticas da técnica.

\section{PALAVRAS-CHAVE}

Cirurgia de nervos periféricos. Neurorrafia término-lateral. Regeneração axonal.

\begin{abstract}
Termino-lateral neurorraphy. A technical evolution for repair of injuries of peripheral nerves? A tremendous amount of progress has taken place in the field of peripheral nerve surgery in the last decades. The development of the surgical microscope and the transoperative eletrophysiological monitoring have resulted in significant improvement in the results of the nerve repair, but until today the termino-terminal suture is still the basic principle of the nerve reconstruction techniques. The terminolateral neurorraphy (end-to-side suture) was developed to be a potential strategy for treating nerve lesions without useable proximal nerve stumps. The literature is replete with reports of clinical and experimental studies about this new surgical technique, but the results are still inconclusive. This study presents a systematic review of the most important papers published in the last ten years in the English literature, including basic research, clinical studies and possible practical applications of this technique.
\end{abstract}

\section{KEY WORDS}

Peripheral nerve surgery. End-to-side neurorrhaphy. Axonal regeneration.

\section{Introdução e evolução histórica}

Os últimos trinta anos foram marcados pelo grande avanço científico observado no entendimento dos mecanismos envolvidos com a regeneração do sistema nervoso periférico, além do avanço técnico obtido com a introdução do microscópio cirúrgico e da monitorização eletrofisiológica transoperatória. A sutura término-terminal sempre permaneceu como o princípio básico da técnica de reconstrução de nervos periféricos. Objetiva o melhor alinhamento possível dos condutos axonais, seja por meio de sutura direta dos cotos do nervo lesado, seja por meio da interposição de enxertos entre eles ${ }^{10}$. Porém essa técnica mostrou limitações em determina- 
das situações, como nos casos em que o acesso a um desses cotos é impossível, ou quando a distância entre eles é grande (o que, em geral, leva a maus resultados operatórios). A neurorrafia término-lateral (NRTL) surgiu na última década como uma alternativa, ainda em investigação, para essas situações em que as técnicas habituais de reparo não podem ser utilizadas. Trata-se da sutura do coto distal de um nervo lesado à face lateral de um nervo vizinho intacto (figura 1), permitindo o crescimento de axônios do último em direção aos tubos endoneurais do primeiro ${ }^{39}$.
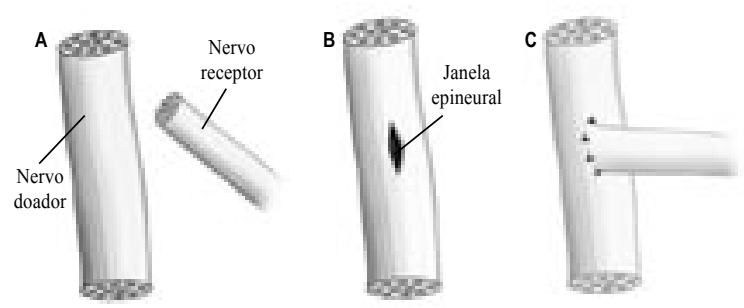

Figura 1 - Esquema da técnica cirúrgica adotada para realização de NRTL. A) aproximação do nervo receptor ao nervo doador; B) confecção de janela epineural; C) sutura epineural término-lateral.

A primeira descrição do uso dessa técnica é referida por Kennedy, em 1899, para o tratamento de espasmo hemifacial. Ballance, em 1903, utilizou-a como forma de tratar um paciente com paralisia facial, suturando o coto distal do nervo facial lesado ao aspecto lateral do nervo acessório ipsilateral, preservando a função deste último. Observou retorno parcial da função motora da face, porém sempre associada aos movimentos do ombro. Também em 1903, Harris experimentou o uso de suturas látero-laterais em pacientes com paralisias obstétricas, obtendo maus resultados. Todas essas tentativas iniciais de induzir crescimento axonal através de suturas término-laterais produziram resultados desapontadores, e a técnica foi abandonada por quase um século 7 .

Em 1992, Fausto Viterbo ${ }^{32,34}$, um cirurgião plástico brasileiro, publicou os resultados de seus experimentos, que demonstravam - com comprovação tanto clínica quanto eletrofisiológica - reinervação da musculatura flexora da perna de ratos após a sutura do coto distal de um nervo fibular, previamente lesado, ao aspecto lateral do nervo tibial ipsilateral intacto. Esses trabalhos provocaram o ressurgimento do interesse pela técnica, estimulando a produção de uma série de pesquisas experimentais em todo o mundo. No fim dos anos 1990, surgiram as primeiras publicações de relatos do uso da NRTL em humanos. O próprio Viterbo demonstrou bons resultados clínicos com a sua utilização para o tratamento de paralisias faciais, tendo usado o nervo facial contralateral como fonte doadora de axônios ${ }^{31}$.

\section{Bases neurobiológicas para o uso da neurorrafia término-lateral}

Após a secção de um nervo periférico, uma série de alterações ocorre tanto no coto proximal como no coto distal desse nervo. Observa-se: edema do corpo do neurônio e aumento da produção de proteínas relacionadas à regeneração do citoesqueleto; degeneração axonal até o nível do último nódulo de Ranvier intacto e, poucas horas após a lesão, já se identificam brotamentos axonais regenerativos no coto proximal. No coto distal ocorre a degeneração axonal walleriana, permitindo a "desobstrução" dos túbulos de endoneuro para o futuro crescimento de axônios regenerados provenientes do coto proximal. Ocorre também a proliferação das células de Schwann, que serão fundamentais para a produção de elementos da matrix extracelular; a liberação de fatores - denominados neurotróficos - que induzem e estimulam o crescimento axonal no coto proximal; produção de fatores que orientam os axônios em direção ao coto distal e facilitam a identificação do túbulo de endoneuro adequado - dito neurotrópicos ${ }^{18}$.

A NRTL permite que os fatores produzidos pelas células de Schwann do nervo lesado - neurotróficos e neurotrópicos - estimulem os axônios do nervo intacto a emitir prolongamentos colaterais que, então, serão capazes de transpor as bainhas nervosas - endo, peri e epineuro - e acabam por reinervar os órgãos-alvo ${ }^{26}$. Esse princípio forma a base neurobiológica da técnica. $\mathrm{Na}$ verdade, o conceito de crescimento colateral de axônios está bem definido desde a década de 1950, quando Exner $^{6}$ demonstrou que, após a desnervação cirúrgica de músculo cricotiroídeo de coelhos, este desenvolvia reinervação a partir de fibras nervosas provenientes de áreas circunvizinhas. Essas fibras se originavam do crescimento colateral de axônios localizados próximos ao músculo desnervado, o que demonstra que os axônios têm capacidade de associação dinâmica com seus alvos, permitindo respostas adaptativas em situações de lesão nervosa. O fenômeno de colateralização caracteriza-se pela formação de um novo prolongamento axonal a partir do nodo de Ranvier mais próximo à área da lesão ou de uma sutura. Torigoe e cols. ${ }^{28}$ demonstraram que, em situações de secção de nervo periférico, as células de Schwann do coto distal induzem crescimento axonal não apenas no coto proximal, como também no nodo de Ranvier proximal ao local da lesão.

\section{Estudos experimentais}

Os primeiros estudos experimentais foram publicados em 1992, pelo grupo de Viterbo ${ }^{32}$, demonstrando, em ratos, que axônios procedentes de um nervo tibial 
intacto podiam ser identificados no coto distal de um nervo fibular lesado quando este era suturado de maneira término-lateral no primeiro, confeccionando-se uma janela epineural no nervo são. Em 1994, o mesmo grupo publicou os resultados quanto à eficácia do método, utilizando o mesmo modelo experimental. Oito meses após a neurorrafia, os animais eram testados eletrofisiologicamente, e os músculos reinervados foram analisados histologicamente. Observaram resposta elétrica na musculatura previamente desnervada em $90 \%$ dos animais. Além disso, as análises histológicas demonstraram um grande número de fibras no nervo fibular, e o peso da musculatura reinervada aproximavase a $70 \%$ do músculo normal ${ }^{34}$.

No mesmo ano, Lundborg e cols. ${ }^{17}$ questionaram qual seria o tipo de axônio induzido ao crescimento colateral, concluindo que tanto axônios motores quanto sensitivos podiam ser identificados no coto distal do nervo lesado, também denominado de "nervo receptor". Além disso, observaram que segmentos distais pré-degenerados apresentavam melhores resultados em termos de crescimento axonal do que suturas com segmentos recém-seccionados. Essa foi a primeira evidência laboratorial da importância das células de Schwann na indução da colateralização axonal. A seguir, o grupo de Viterbo ${ }^{33}$ demonstrou o crescimento axonal mesmo quando enxertos nervosos eram interpostos de forma término-lateral, usando como modelo a NRTL do enxerto ao nervo tibial e término-terminal ao nervo fibular receptor. Desta forma, provaram que com essa técnica os axônios são capazes de cruzar duas linhas de sutura.

As técnicas utilizadas para a realização da sutura término-lateral são muito variadas, havendo divergência entre os autores quanto à necessidade de confecção de janelas epineurais, perineurais ou mesmo sem incisão no nervo são.

$V$ iterbo ${ }^{32}$ preconiza que a presença de epineuro não impede o crescimento axonal. Zhao ${ }^{40}$ demonstrou que as fibras nervosas têm a capacidade de transpor o endo, o peri e o epineuro, apesar de a regeneração nervosa ser mais intensa quando se resseca o epineuro. Por outro lado, o trabalho de Matsumoto ${ }^{19}$ demonstrou que as células de Schwann não conseguem ultrapassar a barreira perineural, e Bertelli e cols. ${ }^{4}$ não observaram crescimento axonal em seu modelo de NRTL em plexo braquial de ratos sem retirada do epineuro. Com o objetivo de esclarecer essa questão, em 1997, Noah e cols. ${ }^{22}$ realizaram um estudo comparativo das possíveis técnicas. Separaram os ratos em quatro grupos: no grupo 1, a NRTL foi feita com preservação do epi e do perineuro; no grupo 2, apenas o epineuro foi removido; no grupo 3, o epi e o perineuro foram removidos; no grupo 4, além da ressecção de epi e perineuro, foi tam- bém realizada a secção de $1 / 3$ da área do nervo. Após trinta dias, foi feita análise histológica do coto distal. Observaram maior contagem de axônios, estatisticamente significativa, nos grupos 3 e 4 (no grupo 4, os axônios provinham de axônios lesados, e não a partir da colateralização), apesar de também ter sido observado crescimento nos grupos 1 e 2, ainda que em menor quantidade. Concluíram que o perineuro forma uma barreira parcial contra a difusão de fatores neurotróficos e neurotrópicos liberados pelas células de Schwann do nervo lesado e que o estímulo ao crescimento colateral induzido pelo coto distal seria mais eficaz com a utilização de janela perineural. Porém é preciso lembrar que a possibilidade de lesão do nervo doador é muito maior com a ressecção do perineuro, o que seria inadmissível na prática clínica. Em 2004, Walker e cols. ${ }^{36}$ analisaram a influência do tamanho da janela perineural na indução de crescimento axonal colateral, observando que janelas de $5 \mathrm{~mm}$ apresentaram maior contagem de fibras quando comparadas com janelas de $1 \mathrm{~mm}$.

Os estudos experimentais também permitiram avaliar a origem dos axônios após a NRTL. Essa questão, durante algum tempo, foi motivo de debate, visto que a maioria das publicações utilizava modelos em que um ramo de um determinado nervo era ressuturado no tronco principal, proximal ou distalmente à emergência desse ramo. Dessa forma, alguns autores alegavam que a fonte de axônios do nervo receptor seriam as fibras nervosas que foram cortadas na secção do nervo, e não a partir da colateralização de axônios íntegros. Em 1998, Zhang e cols. ${ }^{38}$ analisaram três grupos de NRTL com janela epineural: no primeiro foi realizado o modelo básico (nervo fibular suturado ao nervo tibial); o segundo grupo constava do reimplante, de maneira término-lateral, dos ramos para o músculo gastrocnêmio (previamente seccionado) ao nervo tibial; e o terceiro foi submetido à NRTL do coto distal do nervo obturatório (L2-L3) ao nervo ciático (L4-L6). Somente foram identificados axônios de reinervação nos dois primeiros grupos. $\mathrm{O}$ autor concluiu que a NRTL não permitiria reinervação quando os nervos envolvidos se originam de diferentes segmentos medulares.

Por outro lado, usando o mesmo modelo experimental, Noah ${ }^{21}$ observou reinervação do músculo grácil (inervado pelo nervo obturatório), utilizando janela perineural. Chen e Brushart ${ }^{5}$ realizaram o trabalho que iniciou o processo de esclarecimento dessa questão: por meio da marcação retrógrada do corpo de neurônios medulares de ratos, utilizando a técnica de peroxidase eqüina, puderam confirmar que a maioria dos axônios motores de reinervação do nervo receptor era procedente de neurônios intactos, cujo corpo foi marcado no corno anterior da medula, assim como os axônios sensitivos provinham de neurônios não seccionados, 
cujo corpo neuronal estava localizado no gânglio da raiz dorsal. Em 2004, Adelson e cols. ${ }^{1}$ realizaram um estudo em que: 1) identificaram, por meio de dupla coloração retrógrada, a localização dos motoneurônios dos nervos tibial e fibular no corno anterior da medula de ratos; 2) três meses após a NRTL do nervo fibular ao nervo tibial, realizaram a marcação retrógrada do nervo tibial com uso de fluoroemerald a $5 \%$ e, do nervo fibular, com fluororuby a $5 \%$. Observaram presença de marcador fluororuby 5\% na área do corno anterior da medula relacionada ao nervo tibial. Dessa forma, confirmou-se que os axônios motores de reinervação do nervo fibular derivavam-se do crescimento colateral de axônios intactos procedentes do nervo tibial.

Os estudos que avaliaram em animais os resultados funcionais da NRTL demonstram conclusões conflitantes. Tarasidis e cols. ${ }^{27}$ analisaram os resultados da técnica por meio de testes funcionais (força da passada), eletrofisiológicos, avaliação de massa muscular, marcação retrógrada e avaliação histológica. Encontraram resultados pobres em todos os critérios, excetuando-se a marcação retrógrada, pois o gânglio da raiz dorsal foi marcado na maioria dos animais. Concluíram que a técnica permite resultados adequados apenas quanto à reinervação sensitiva. Por outro lado, Than e Morrinson ${ }^{29}$, utilizando modelo de reimplante de ramo do gastrocnêmio no nervo tibial, por meio de sutura término-lateral, observaram $80 \%$ de reinervação e recuperação motora após 12 semanas. Liu e cols. ${ }^{14}$ também puderam observar reinervação da musculatura anterior da perna de ratos após NRTL, obtendo bons resultados em análises de função motora e de marcha. Kalliainen e cols. ${ }^{9}$ não observaram diferença, com relação à força de contração muscular isométrica ou específica, quando compararam grupos de ratos submetidos à sutura término-lateral ou término-terminal. Deve-se questionar o método usado pelos autores individualmente, visto que a escolha do nervo doador parece ser de fundamental importância para a obtenção de bons resultados do ponto de vista funcional. O modelo clássico utilizado na maioria dos trabalhos (NRTL fibular-tibial) resulta na contração simultânea de musculatura agonista e antagonista da perna. Nesses casos, as análises eletrofisiológicas e histológicas mostrarão excelentes resultados, mas funcionalmente 0 mesmo pode não ocorrer. O elegante estudo de Lutz ${ }^{16}$, em 2000, comprovou isso: utilizando modelo de lesão de nervo mediano, o autor realizou NRTL desse nervo ao radial (antagonista) e ao nervo ulnar (agonista). Nenhum dos animais do grupo suturado ao nervo radial demonstrou recuperação funcional, enquanto $2 / 3$ daqueles em que a rafia foi feita no nervo ulnar apresentaram recuperação de até $70 \%$ da força final dos músculos reinervados, quando comparados com um grupo-controle submetido à sutura término-terminal do nervo mediano lesado. O estímulo elétrico no nervo radial resultava em co-contração da musculatura extensora e flexora, o que ainda assim não resultou em utilidade funcional para os animais.

\section{Estudos clínicos}

A sutura término-lateral é uma técnica recente incorporada aos recursos do cirurgião de nervos periféricos, sendo ainda considerada experimental. Devido a isso, existem poucos relatos do seu uso em humanos, sendo a maioria restrita a séries muito pequenas ou relatos de caso.

Viterbo ${ }^{30}$ foi um dos primeiros a utilizar esse tipo de técnica para o tratamento de paralisia facial periférica unilateral. Conectou o coto distal de ramos periféricos do nervo facial lesado ao nervo facial íntegro contralateral, utilizando a NRTL para a interposição de cabos de enxerto de nervo sural sem provocar lesão no nervo doador. Em alguns pacientes selecionados, observou reinervação do músculo orbicular dos olhos e da musculatura facial inferior. Também relatou o uso dessa técnica para minimizar a disestesia provocada pela retirada do nervo sural, confeccionando NRTL do coto distal deste ao nervo fibular superficial ${ }^{31}$.

Em 1999, Ogun e cols. ${ }^{23}$ relataram uma pequena série de três pacientes com lesões muito extensas de nervo mediano no antebraço, nos quais o coto distal desse nervo foi suturado de maneira término-lateral ao nervo ulnar ipsilateral. Apenas um dos casos obteve força M4 (MRC) no músculo abdutor curto do polegar; os demais não apresentaram sinais de reinervação após 38 meses de acompanhamento. Em 2002, Koh e cols. ${ }^{12}$ relataram o uso dessa técnica em quatro pacientes submetidos a anastomose hipoglosso-facial, suturando o coto distal de um enxerto de nervo sural ao coto distal do nervo facial e o coto proximal do enxerto ao nervo hipoglosso íntegro, por meio de NRTL; ou ainda o próprio coto distal do nervo facial ao nervo hipoglosso através de NRTL. Relataram a obtenção de simetria facial em todos os casos. Yuksen e cols. ${ }^{37}$ reportaram o uso da NRTL para tratamento de uma lesão extensa de nervo ulnar (suturado ao nervo mediano) e para o reparo de uma lesão do nervo mediano em que não era possível o acesso ao coto proximal (suturado ao nervo ulnar). Houve recuperação parcial da sensibilidade e fraca recuperação motora (M3) da mão afetada nos dois casos. Bertelli e Ghizoni ${ }^{3}$, em 2003, reportaram sete lesões de nervos periféricos tratadas com NRTL, não observando recuperação clínica ou eletrofisiológica em nenhum deles. 
Deve-se a Mennen ${ }^{20}$, em 2003, e a Pienaar e cols. ${ }^{24}$, em 2004, as maiores séries da literatura a respeito do uso das NRTL na prática clínica, sendo os resultados conflitantes. O primeiro utilizou a técnica em 56 pacientes com lesões variadas, envolvendo desde plexo braquial até lesões de nervos digitais. Concluiu que a NRTL provou ser muito útil em situações em que não é possível o uso das técnicas habituais, podendo inclusive substituir o uso de enxertos muito longos em alguns casos selecionados. Por outro lado, o trabalho de Pienaar e cols. concluiu o contrário: avaliando o resultado de 20 pacientes em que a técnica foi utilizada como opção, não observou evidências de recuperação em nenhum dos pacientes em que foi feito um adequado acompanhamento. Esses autores relatam que abandonaram essa técnica devido aos maus resultados obtidos. Para adequada análise desses trabalhos, deve-se levar em conta que, no estudo de Pienaar, mais da metade dos casos era de lesões do plexo braquial ou de lesões altas de nervo ulnar/mediano, provocadas principalmente por lesões de arma branca, o que pode ter interferido nos resultados finais. Além disso, o artigo de Mennen incluía lesões de nervo digital, que, aparentemente, respondem muito bem a esse tipo de técnica, visto que Voche e Ouattara ${ }^{35}$ relataram o uso da NRTL para tratamento de dez lesões desses nervos ao nível da palma da mão ou em dedos, observando reinervação sensitiva parcial em todos.

\section{Pontos vulneráveis e possíveis utilizações práticas da técnica}

A grande quantidade de experimentos laboratoriais já realizados tem permitido um avanço significativo na melhor compreensão dos mecanismos neurobiológicos envolvidos no processo de formação de colaterais axonais em função da NRTL. Porém diversas questões ainda devem ser respondidas para que o uso dessa técnica passe a ser ampliado na prática clínica, tais como:

a) Quais os efeitos da colateralização axonal sobre o nervo doador? Existe possibilidade de esse fenômeno diminuir a ação motora ou sensitiva desse nervo?

b) Qual(is) o(s) mecanismo(s) que permite(m) com que o nervo doador possa inervar dois alvos diferentes?

c) Qual a capacidade-limite de colateralização de um determinado nervo? O seu limite é suficiente para proporcionar reinervação funcionalmente útil ao nervo lesado?

d) Qual é a performance funcional limítrofe de um nervo "receptor"? e) Os axônios do nervo doador reinervam as placas motoras previamente existentes ou formam-se novas placas?

As respostas a essas questões poderão auxiliar o cirurgião, em um futuro breve, a decidir pelo uso de enxertos ou pela realização de NRTL em alguns casos de lesões em que não é possível a sutura direta dos cotos de determinado nervo. Os resultados funcionais com uso de enxertos de nervos não são completamente satisfatórios. Os dados publicados oferecem números variados em relação à quantidade de axônios que são capazes de cruzar duas linhas de sutura (a taxa varia entre $30 \%$ e $50 \%)^{25}$. Os estudos experimentais demonstram que, nos casos de NRTL, o número de axônios que atravessam a sutura gira em torno de $47 \%^{33}$. Avaliando nesses termos, as duas técnicas se equivalem.

A revisão de literatura até o presente momento demonstra que a técnica de NRTL já apresenta algumas utilidades clínicas em situações específicas, além de algumas utilizações possíveis que necessitam de comprovação tanto laboratorial quanto clínica. Relataremos agora essas possibilidades, lembrando que algumas delas ainda se encontram apenas no campo da teoria.

Na prática clínica, já está comprovado o potencial da NRTL para o tratamento de determinados tipos de paralisias faciais, como a técnica desenvolvida por Viterbo $^{30}$, denominada facial crossover, adotada em diversos centros $^{8,13}$, e que leva a resultados favoráveis em termos de recuperação funcional. Outra situação em que está sendo utilizada, com freqüência crescente, é nos casos em que não há possibilidade de acesso ao coto proximal. Esta é, atualmente, a condição em que a técnica é mais freqüentemente utilizada em cirurgias de nervos das extremidades, porém os resultados ainda são muito pobres ${ }^{23,37}$. Uma exceção a tal regra parecem ser as lesões de nervos digitais, tanto no nível da palma da mão quanto em dedos, pois os trabalhos publicados sobre esse tema demonstram reinervação sensitiva na maioria dos pacientes ${ }^{35}$. Provavelmente, esses bons resultados devem-se ao fato de esses nervos serem unicamente sensitivos e, talvez, essa regra possa se estender a lesões de outros nervos também puramente sensitivos, o que ainda necessita de investigação.

Viterbo $^{31}$ descreveu o uso da NRTL para o tratamento de disestesias no território do nervo sural quando este é ressecado para obtenção de enxertos nervosos. O coto distal desse nervo poderia ser suturado ao nervo fibular superficial ipsilateral, com o objetivo de obter reinervação sensitiva da região. Essa técnica necessita de comprovação em séries maiores e controladas. Outra interessante possibilidade do uso da NRTL seria no tratamento de neuromas dolorosos. Existem alguns estudos laboratoriais demonstrando a possibilidade de 
sutura do coto distal do nervo lesado em seu próprio tronco, rodando-o posteriormente (figura 2). Low e cols. ${ }^{15}$ avaliaram essa possibilidade em ratos, tendo suturado o coto proximal do nervo fibular seccionado ao nervo ciático ipsilateral, comparando o resultado com controles em que o coto foi deixado sem tratamento. Observaram formação de neuromas estatisticamente menores no grupo de estudo, com o tecido de regeneração orientado de maneira mais ordenada do que nos controles. Ainda não existem trabalhos utilizando essa técnica em humanos.

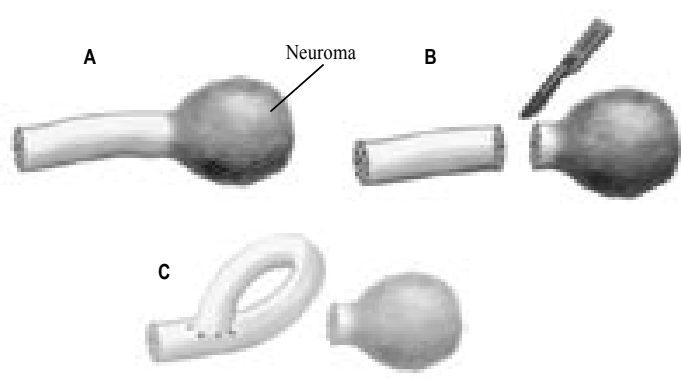

Figura 2 - Uso da técnica de sutura término-lateral para tratamento de neuroma doloroso. A) neuroma traumático distal e doloroso; B) ressecção do neuroma; $C$ ) sutura término-lateral do coto distal no próprio nervo.

Alguns autores preconizam que a NRTL apresentaria como vantagem sobre as interposições de enxertos a necessidade de apenas uma sutura, que ainda poderia ser confeccionada próxima ao órgão-alvo ${ }^{39}$. Dessa forma, existem relatos do seu uso como alternativa em situações nas quais os enxertos utilizados deveriam ser muito longos (geralmente maiores que $20 \mathrm{~cm}$ ). Os resultados ainda não podem ser adequadamente avaliados, visto o pequeno número de casos descritos para essa situação ${ }^{2}$. Outra possibilidade teórica do uso da técnica seria sua utilização naquelas lesões localizadas muito afastadas dos órgãos-alvo e que apresentam reconhecidamente mau prognóstico funcional. Exemplos dessa situação seriam os casos de lesões muito proximais de nervos ulnar ou mediano, em que o paciente é visto tardiamente pela primeira vez. O cirurgião poderia abrir mão da tentativa de reconstrução dessas estruturas e optar por uma sutura término-lateral entre nervos mais distais, próxima ao órgão-alvo. Por exemplo: em uma lesão do nervo ulnar na axila com mais de um ano de evolução, uma NRTL do nervo ulnar no nervo mediano poderia ser confeccionada mais próximo à mão, como alternativa à reconstrução com interposição de enxertos. Não existe nenhum trabalho ou relato de caso desse tipo de situação, sendo unicamente hipotética.
Recentemente abriu-se uma nova frente de estudos avaliando a utilidade dessa técnica no tratamento do neuroma-em-continuidade. Nessas situações, os trabalhos experimentais demonstram que, mesmo naqueles ditos eletricamente "silenciosos", alguns axônios conseguem ultrapassar a lesão. O seu tratamento-padrão inclui testes eletrofisiológicos (NAPs) transoperatórios, e, caso estes sejam negativos, procede-se à ressecção da lesão e à reconstrução do nervo por meio do uso de enxertos ${ }^{10}$. Portanto, utilizando a técnica convencional, o cirurgião sacrificaria esses poucos axônios que foram capazes de ultrapassar o neuroma. Dois estudos recentes ${ }^{1,11}$ iniciaram a investigação do uso da NRTL como forma de poupar esses axônios. O método usado foi semelhante nos dois trabalhos: de início, foi realizada uma lesão no nervo ciático de ratos, aguardando-se a formação de neuroma. Em um segundo procedimento, os autores realizavam duas suturas término-laterais de enxertos nervosos, uma proximal e outra distalmente à lesão, formando uma "ponte" ao redor desta (figura 3). Os controles eram deixados sem correção. Ambos os estudos mostraram que houve regeneração nervosa, comprovada tanto por análise eletrofisiológica quanto histológica, nos nervos tratados dessa forma.
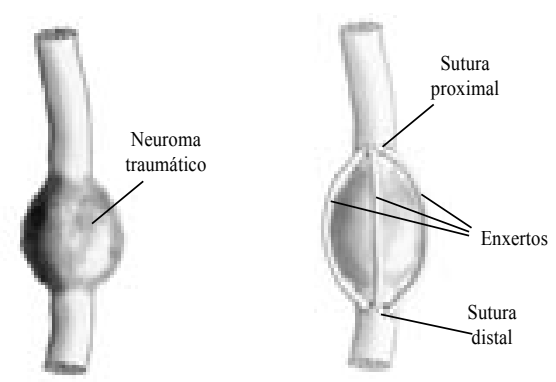

Figura 3 - Experimentos com uso da NRTL para tratamento do neuroma-em-continuidade. A) neuroma-em-continuidade; B) interposição de enxertos nervosos, suturados de maneira término-lateral proximal e distalmente ao neuroma, preservando a lesão e a continuidade do nervo envolvido.

\section{Conclusão}

A NRTL abriu uma nova perspectiva no tratamento das lesões do sistema nervoso periférico. Trata-se de uma técnica recente, bastante investigada em laboratórios e com alguns relatos preliminares de sua utilização na prática clínica. Os estudos experimentais acenam com bons resultados em termos de reinervação do nervo "receptor" em animais, porém a mesma performance ainda não pôde ser observada em humanos. Além disso, muitas questões precisam ser esclarecidas 
e aguardam-se estudos controlados, que até hoje não foram realizados. Mas, acima de tudo, estamos atualmente assistindo aos primeiros passos de uma técnica que, a depender de comprovação da sua eficácia, tem a possibilidade de revolucionar futuramente a cirurgia de nervos periféricos.

\section{Agradecimento}

O autor agradece à Sra. Adriana Mayon Neiva Flores pela prestimosa colaboração ao desenhar as figuras apresentadas neste trabalho.

\section{Referências}

1. ADELSON PD, UGENE E, BONAROTIEA, TODD TP, TRAN $M$, NYSTROM NA: End-to-side neurorrhaphies in a rodent model of peripheral nerve injury: a preliminary report of a novel technique. J Neurosurg (Ped) 101:71-84, 2004.

2. AMR SM, MOHARRAM AN: Repair of brachial plexus lesions by end-to-side side-to-side grafting neurorrhaphy: experience based on 11 cases. Microsurgery 25: 126-46, 2005.

3. BERTELLI JA, GUIZONI MF: Nerve repair by end-to-side coaptation or fascicular transfer: a clinical study. J Reconstr Microsurg 19:313-8, 2003.

4. BERTELLI JA, SOARES DOS SANTOS AR, CALIXTO JB: Is axonal sprouting able to transverse the conjunctival layers of the peripheral nerve? A behavioural, motor and sensory study of end-to-side nerve anastomosis. J Recontr Microsurg 12:559-63, 1996.

5. CHENYG, BRUSHART TM: The effect of denerveted muscle and Schwann cells on axonal collateral sprouting. J Hand Surg (Am) 23:1025-33, 1998.

6. EXNER MV: Collateral nerve regeneration. Quart Res Biol 28:260-76, 1953

7. HATA Y: The real history of end-to-side neurorrhaphy. $\mathrm{Br} \mathrm{J}$ Plast Surg 53:633-4, 2000.

8. KAKIBUSHI M, TUJI K, FUKUDA K, TERADA T, KAVAI K, YANO K: End-to-side nerve graft for facial nerve reconstruction. Ann Plast Surg 53:496-500, 2004

9. KALLIAINEN LK, KUZON WM: Reinnervating skeletal muscle using termino-lateral neurorrhaphy. J Reconstr Microsurg 13:136-40, 1997.

10. KERNS JM, SLADEK EH, MALHSHITE TS, BACH H, GONZALES MH: End-to-side nerve grafting of the tibial nerve to bridge a neuroma-in-continuity. Microsurgery 25:155-66, 2005.

11. KLINE DG, HUDSON AR: Nerve injuries. Operative results for major nerve injuries, entrapments and tumors. Philadelphia, WB Sauders, 1995.

12. KOH KS, KIM CJ, KWUM BD, KIM SY: Hipoglossal-facial crossover in facial-nerve palsy: pure end-to-side anastomosis technique. Br J Plast Surg 55:25-31, 2002.

13. KRIVOLUTSKAIAEG, CHUMASOV EL, MATINA VN, MELTSOVA GM, KIRILLOV AL: End-to-side type of plastic repair of the facial nerve branches. Stomaltologia 68:35-8, 2003.
14. LIU K, CHEN LE, SEABER AV: Motor functional and morphological findings followig end-to-side neurorrhaphy in a rat model. J Orthop Res 17:293-300, 1999.

15. LOW CK, CHEW SH, SONG IC, NYG TH, LOW YP: End-toside anastomosis of transected nerves to prevent neuroma formation. Clin Orthop Relat Res 369:327-32, 1999.

16. LUNDBORG G, ZHAO Q, KANJE M, KERNS JM: Can sensory and motor collateral sprouting be induced from intact peripheral nerve by end-to-side anastomosis? J Hand Surg (Br) 19:277-82, 1994

17. LUTZ BS, CHUANG DCC, HSU JC, WEI FC: Selection of donor nerves - an important factor in end-to-side neurorrhaphy. Br J Plast Surg 53:149-54, 2000.

18. MARTINS RS, SIQUEIRA MG, da SILVA CF, PLESE JPP Mecanismos básicos da regeneração de nervos. Arq Bras Neurocir 24:20-5, 2005.

19. MATSUMOTO M, HIRATA H, NISHIYAMA M, SASAKI H, UCHIDA A: Schwann cells can induce collateral sprouting from intact axons: experimental study of end-to-side neurorrhaphy using Y-chamber model. J Reconstr Microsurg 15:281-6, 1999

20. MENNEM U: End-to side nerve suture in clinical pratice. Hand Surg 8:33-42, 2003.

21. NOAH EM, WIILIAMS A, FORTES W: A new animal model to investigate axonal sprouting after end-to-side neurorrhaphy. J Reconstr Microsurg 13:317-25, 1997.

22. NOAH EM, WIILIAMS A, JORGENSON C, TERZIS JK: End-to-side neurorrhaphy: a histological and morphometric study of axonal sprouting into an end-to-side nerve graft. J Reconstr Microsurg 13:99-106, 1997.

23. OGUN TC, OZDEMIR M, SENARAN H, USTUN ME: End-to-side neurorrhaphy as a salvage procedure for irreparable nerve injuries. Technical note. J Neurosurg 99:180-5, 2003.

24. PIEENAR C, SWAN MC, DE JAGER W, SOLOMONS M: Clinical experience with end-to-side nerve transfer. J Hand Surg (Br) 29:438-43, 2004.

25. RAYMENT R, POOLE MD, RUSHWORTH G: Cross-facial nerve transplant: why are spontaneous smiles not restored? Br J Plast Surg 40:592-7, 1987.

26. ROWAN PR, CHEN LE, URBANIAK JR: End-to-side nerve repair. A review. Hand Clin 16:151-9, 2000.

27. TARASIDIS G, WATANABE O, MACKINON S: End-to-side neurorrhaphy resulting limited sensory axonal regeneration in a rat model. Ann Otol Rhinol Laryngol 106:506-12, 1997.

28. TORIGOE, K, TANAKA, HG, TAKAHASHI A, HASHIMOTO $K$ : Early growth of regenerating neurites in arylamide neuropathic mice: applications of a film model. Brain Res 746:269-74, 1997.

29. THAN SKY, MORRISON WA: Motor collateral sprouting through an end-to-side nerve repair. J Hand Surg 23:84451, 1998.

30. VITERBO F: Novo método para o tratamento da paralisia facial: o "cross-facial nerve" com neurorrafia término-lateral. Rev Soc Bras Cir Plast Est Recontr 8:29-35, 1993.

31. VITERBO F: Neurorrafia término-lateral. In TATAGIBA M, PEREIRA CU (eds): Nervos periféricos. Tratamento clínico e cirúrgico. Rio de Janeiro, Ed. Revinter, pp 85-87, 2003.

32. VITERBO F, TRINDADE JC, HOSHINO K, MAZONI A: Latero-terminal neurorrhaphy without removal of epineural sheath: an experimental study in rats. Rev Pau Med 110:26775, 1992

33. VITERBO F, TRINDADE JC, HOSHINO K, NETO AM: End-to-side neurorrhaphy with removal of the epineural sheath: an experimental study in rats. Plast Reconstr Surg 94:1038-47, 1994. 
34. VITERBO F, TRINDADE JC, HOSHINO K, NETO AM: Two end-to-side neurorrhaphies and nerve graft with removal of the epineural sheath: an experimental study in rats. $\mathrm{Br} \mathrm{J}$ Plast Surg 47:75-80, 1994.

35. VOCHE P, QUATTARA D: End-to-side neurorrhaphy for defects of palmar sensory digital nerves. $\mathrm{Br} \mathrm{J}$ Plast Surg 58:239-44, 2005.

36. WALKER JC, BRENNER MJ, MACKINNON SE, WINOGRAD JM, HUNTER DA: Effect of perineural window size on nerve regeneration, blood-nerve barrier integrity and functional recovery. J Neurotr 2:217-27, 2004.

37. YUKSEL F, PEKER F, CELIKOZ B: Two applications of end-to-side nerve neurorrhaphy in severe upper-extremity nerve injuries. Microsurgery 24:363-8, 2004.

38. ZHANG F, CHENG C, CHIN BT, HO PR, WEIBEL TJ, LINEAWEAVER WC et al.: Results of termino-lateral neurorrhaphy to original and adjacents nerves. Microsurgery 18:276-81, 1998.

39. ZHANG F, FISHER KA: End-to-side neurorrhaphy. Microsurgery 22:122-7, 2002.

40. ZHAO JZ, CHEN ZW, CHEN TY: Nerve regeneration after terminolateral neurorrhaphy: experimental study in rats. J Reconstr Microsurg 13:31-7, 1997.

Original recebido em outubro de 2005

Aceito para publicação em março de 2006

\section{Endereço para correspondência:}

Leandro P. Flores

SQN 208 Bloco F Apt. 604

70853-060 - Brasília, DF

Email: leandroprettoflores@hotmail.com

\section{Comentários}

O presente trabalho de revisão sobre neurorrafia término-lateral é bastante completo e reflete as incertezas ainda existentes sobre a aplicação prática dessa técnica.

As publicações de trabalhos de pesquisa sobre a técnica de neurorrafia término-lateral têm aumentado consideravelmente. Uma crítica a ser feita a eles é o fato de que, em sua grande maioria, empregam modelos experimentais com ratos, cuja capacidade de regeneração é muito maior que a de seres humanos. De forma ideal, esses trabalhos deveriam utilizar modelos experimentais com primatas, tendo em vista sua regeneração axonal semelhante à dos humanos.
No entanto, só existe um trabalho publicado com esse tipo de modelo ${ }^{1}$ e outro submetido a publicação (Kline DG, 2005 - comunicação pessoal).

As aplicações clínicas da neurorrafia términolateral ainda não foram completamente definidas, e séries e relatos de casos utilizando essa técnica ainda são escassos e contraditórios. A meu ver, com base nas informações existentes no momento, é razoável assumir-se que o reparo término-terminal sempre resultará em melhor regeneração axonal que o reparo términolateral, e que este último só deverá ser empregado quando o primeiro não for possível. Uma recuperação motora funcional após neurorrafia término-lateral não é previsível, e o método deve ser reservado principalmente para situações clínicas nas quais a sensibilidade é a principal função a ser restaurada. A verdadeira importância da neurorrafia término-lateral só será estabelecida quando forem realizados ensaios clínicos controlados que comparem essa nova técnica com as técnicas já estabelecidas para reparo de nervos.

Apesar de a intenção dos autores de artigos de revisão ser bastante abrangente, é natural que escapem publicações em seus levantamentos bibliográficos. Com a finalidade de colaborar para que este artigo de revisão seja o mais completo possível, devo mencionar duas publicações que não constam da bibliografia: o relato de Kayikçioglu e cols. sobre o resultado negativo de neurorrafias término-laterais dos nervos ulnar e mediano no punho ${ }^{2}$ e o extenso trabalho de revisão de Al-Qattan ${ }^{3}$.

O presente artigo é excelente e certamente será de grande utilidade para os neurocirurgiões envolvidos no tratamento de lesões de nervos periféricos.

1. MENNEN U: End-to-side nerve suture in the primate (Chacma baboon). Hand Surg 3:1, 1998.

2. KAYIKÇIOGLU A, KARAMÜRSEL S, AGAOGLU G, KEÇIK A, ÇELIKER R, ÇETIN A: End-to-side neurorrhaphies of the ulnar and median nerves at the wrist: report of two cases without sensory or motor improvement. Ann Plast Surg 45:641-3, 2000.

3. AL-QATTAN MM: Terminolateral neurorrhaphy: review of experimental and clinical studies. J Reconstr Microsurg 17:99-108, 2001.
Mário Siqueira

Editor 